\section{Chilades pandava Damage among 85 Cycas Species in a Common Garden Setting}

\author{
Thomas E. Marler ${ }^{1}$ \\ Western Pacific Tropical Research Center, College of Natural and Applied \\ Sciences, University of Guam, UOG Station, Mangilao, Guam 96923
}

Anders J. Lindström

Nong Nooch Tropical Botanical Garden, 34/1 Sukhumvit Hgw, Najomtien, Sattahip, Chonburi 20250, Thailand

\section{Irene Terry}

Western Pacific Tropical Research Center, College of Natural and Applied Sciences, University of Guam, UOG Station, Mangilao, Guam 96923

Additional index words. Cycadaceae, leaf traits, plant-arthropod interactions, plant defense, volatiles

\begin{abstract}
The extent of Chilades pandava Horsfield herbivory among 85 Cycadaceae species was determined by three evaluators in a common garden setting in Thailand to identify patterns that may improve horticultural and conservation management practices. The significant differences in herbivory damage from this invasive lepidopteran pest ranged 8.7-fold among the species. Phylogenetic sections of this monogeneric cycad family did not correspond to the relative differences among the species, and country of nativity was also not informative for this purpose. We suggest the Cycas $\mathbf{L}$. species that share native habitat with this butterfly or the closely related Theclinesthes onycha Hewitson are among the least damaged taxa when they are comingled with other Cycas species in a common landscape. Grouping the most damaged Cycas species together in a managed landscape may reduce costs associated with plant protection. The inclusion of non-native $C y c a s$ plants in gardens nearby native $C y c a s$ habitats carries the potential of disrupting the delicate specialist relationship that native butterfly populations have with host Cycas species.
\end{abstract}

Invasive arthropod herbivores comprise one of the greatest threats to cycad conservation both in situ and ex situ. The lepidopteran Chilades pandava (Plains Cupid Butterfly, Fig. 1B) is a specialist insect native to southern Asia that invaded Guam in recent years (Moore et al., 2005), and it is among the invasive species that are collectively threatening the endemic Cycas micronesica K.D. Hill (Marler and Lawrence, 2012). This insect depends on a sustained close relationship with native Cycas within its indigenous range. It causes extensive damage to Cycas populations within habitats in its invasive range like Guam. These factors engender a horticultural conflict between the need to protect Cycas species from damage within garden settings and within the butterfly's invasive range and the arguable need to conserve its dependence on Cycas plants in situ.

An extensive ex situ germplasm collection of Guam's C. micronesica was established at

Received for publication 22 Aug. 2012. Accepted for publication 10 Oct. 2012.

Support provided by U.S. Forest Service Project No. 10-DG-11059702-095.

We thank George Fernandez for statistical analyses. ${ }^{1}$ To whom reprint requests should be addressed; e-mailtmarler@uguam.uog.edu.
Nong Nooch Tropical Botanical Garden in Thailand as part of our efforts to conserve this endangered cycad. In this setting where the butterfly is native, herbivory is highly heterogeneous among comingled Cycas species. Some species like Cycas revoluta Thunb. (Fig. 1C) and C. micronesica (Fig. 1E) exhibit extensive, unsightly damage, whereas other species exhibit minimal damage (Figs. 1D and $1 F)$. Management decisions for this situation would benefit from understanding how the butterfly relates to its native host Cycas species in natural habitats and how it relates as a pest to novel Cycas host species in horticultural settings.

Most of the 107 described Cycas species (Osborne et al., 2012) are being conserved in the ex situ cycad germplasm collections in Nong Nooch Tropical Botanical Garden. Pesticide protection of susceptible Cycas taxa resulting from this pest represents one of the greatest costs for success of these conservation efforts. We used this germplasm collection growing in a common garden setting to determine relative butterfly herbivory at the species level. Our objective was to then mine these data for linkages between resistance to damage and group traits that may reduce uncertainty in predictions of and expose mechanisms that explain disparity in butterfly damage.
Three evaluators conducted this survey to quantify the extent of damage to representative field-planted Cycas species at Nong Nooch Tropical Botanical Garden in Thailand. The survey included 85 species growing in homogeneous abiotic and insect pressure conditions. Two arthropods exhibit chronic pest pressures on the Cycas plants in this garden, Chilades pandava and Aulacaspis yasumatsui Takagi. The butterfly can feed on several tissue types, but for every substrate, it requires expanding tissue for ovipositioning and caterpillar food. The various groups of Cycas species produce vegetative flushes at varied times of the year, and some exotic Cycas taxa produce leaves throughout the year. These characteristics provide the resident butterfly population with a sustained supply of caterpillar food. Therefore, the pest pressures are relentless and constant throughout the year so that no matter when a Cycas has a flush of leaves, it is subjected to adult butterfly ovipositioning. A. yasumatsui, the second resident Cycas pest in our garden, is an armored scale that infests any organ that presents live exposed surfaces. Unidentified biological control organisms keep the widespread A. yasumatsui infestations from irrupting. Confusing the plant damage imposed by these two arthropods is not possible; therefore, identifying butterfly damage is unambiguous.

Individual plants were ranked for butterfly damage in Mar. 2012. We assigned 0 for a plant exhibiting no visible damage and 10 for a plant with butterfly damage on every leaf. A total of 673 plants in 85 species, representing all five Cycas sections, were evaluated. A Poisson regression model was fitted on log-transformed damage evaluation scores using SAS GLIMMIX procedure in Version 9.3 (SAS Institute Inc., Cary, NC). A Type III test of fixed main effects was used to determine significance of evaluators and species. The damage differences among the species were determined using pairwise comparison of least squares means on log scale.

\section{Results and Discussion}

The mean damage score among species was significant based on Type III test ( $P \leq$ $0.0001)$ after removing the evaluator differences. The log-transformed mean damage scores were back-transformed and presented as a LSMEANs table (Table 1). Butterfly damage of the 85 Cycas species in this common garden setting exhibited an overall mean of 2.093, and mean damage ranged 8.7-fold among the species $(0.5947$ to 5.1502$)$. The damage scores for these species partitioned into 18 overlapping groups. Clearly, whether Cycas plants succumb to or resist damage by chronic butterfly pressure is governed by differences expressed at the species level.

Phylogeny. Cycas micronesica, C. petraea A. Lindstr. \& K.D. Hill, C. revoluta, C. seemannii A. Braun, C. tansachana K.D. Hill \& S.L. Yang, and C. thouarsii R.Br. ex Gaudich. emerged as the most damaged 

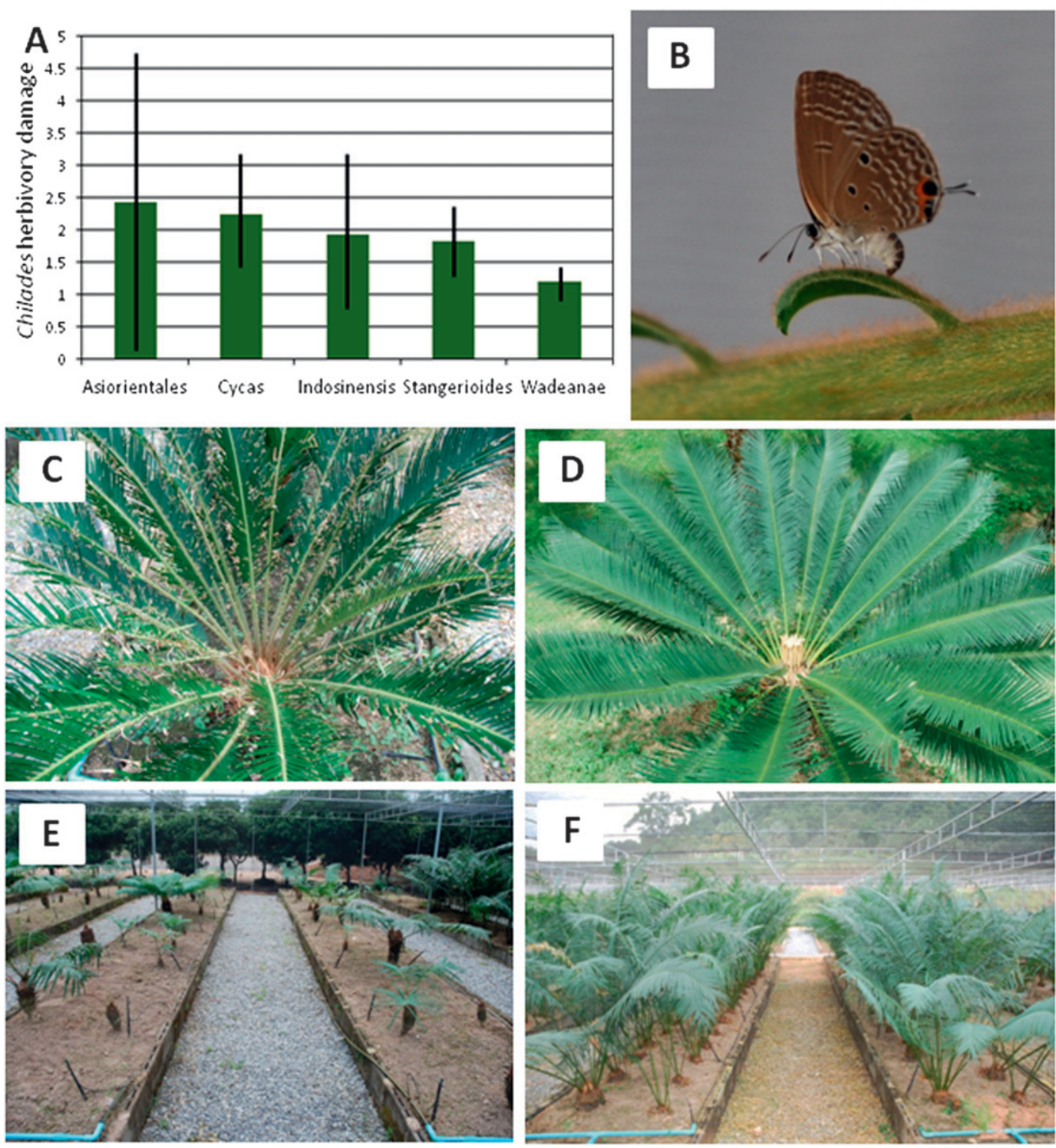

Fig. 1. Relationship of Cycas species with the specialist herbivore Chilades pandava. (A) Extent of herbivory damage for 85 Cycas species sorted into the five Cycadaceae sections, mean \pm SD. (B) Female butterfly ovipositioning eggs on Cycas revoluta leaf. (C) C. revoluta plant showing typical extensive butterfly damage to leaflets. Damage score $\approx 9$. (D) C. pachypoda plant with undamaged leaves. Damage score 0. (E) Production beds of the susceptible C. micronesica showing plant mortality and heterogeneous growth. (F) Production beds of the resistant $C$. chamaoensis showing homogeneous growth.

species and C. aculeata K.D. Hill \& T.H. Nguyên, C. circinalis L., C. condaoensis K.D. Hill \& S.L. Yang, C. pachypoda K.D. Hill, C. pruinosa Maconochie, C. taitungensis C.F. Shen, K.D. Hill, C.H. Tsou \& C.J. Chen, $C$. tuckeri K.D. Hill, and C. wadei Merrill exhibited the least amount of damage among the 85 species (Table 1). Exploring characteristics that explain these two extreme groups may establish a foundation for understanding the controlling mechanisms of the disparity in damage within the genus. Two obvious group traits to explore for this purpose are phylogenetic sections and native biogeographic range.

The 107 species (Osborne et al., 2012) that comprise the Cycadaceae are classified into five sections (Hill, 2004) based primarily on morphological characters. Mean damage score for these sections exhibited a 2-fold non-significant range (Fig. 1A). The section Asiorientales, distinguished by tomentose ovules, provides an example of the immense variation within each of these sections. Asiorientales exhibited a mean score that was greater than the overall survey mean, contained $C$. taitungensis in the least damaged group, and $C$. revoluta in the most damaged group. These major Cycas sections do not adequately inform our understanding of what underlies the differences in butterfly damage among the 85 species that we observed.

Our results do not broadly correspond with phylogeny. However, the non-significant lower damage scores in this garden survey for the species in the Wadeanae section indicate that direct bioassays may show this section to be more resistant than the other sections. Furthermore, one smaller group of species emerges as highly damaged relative to the overall list of Cycas species. The Rumphiae subsection of the Cycas section (Hill, 2004) is distinguished by spongy tissue within the seed sclerotesta. When fully developed, this tissue enables oceanic seed dispersal (Dehgan and Yuen,
1983). The mean for the eight species from this subsection in our survey was 3.1281, and half of the Cycas species ranked as most damaged (Table 1) were from this small subsection. An interesting example that underscores these observations is the Philippine island of Culion, where the strict endemic $C$. wadei (Wadeanae section without floating seeds) and the widespread $C$. edentata de Laub. (Rumphiae subsection within Cycas section with floating seeds) live on the main island and its barrier islands (Lindström et al., 2008). Damage to $C$. edentata was three times greater than that to $C$. wadei, and it is ranked among the top 10 most damaged species (Table 1). Although this efficient long-distance seed dispersal mechanism enables colonization of remote islands to establish an extensive indigenous range, dispersal to an uninfested location may preclude or at least delay the butterfly or any other specialist from establishing in the new location. 
Table 1. Extent of Chilades pandava herbivory among 85 Cycas species growing at Nong Nooch Tropical Botanical Garden in Thailand, native biogeographic range, and Cycadaceae section based on Hill (2004). ${ }^{\mathrm{C}}$

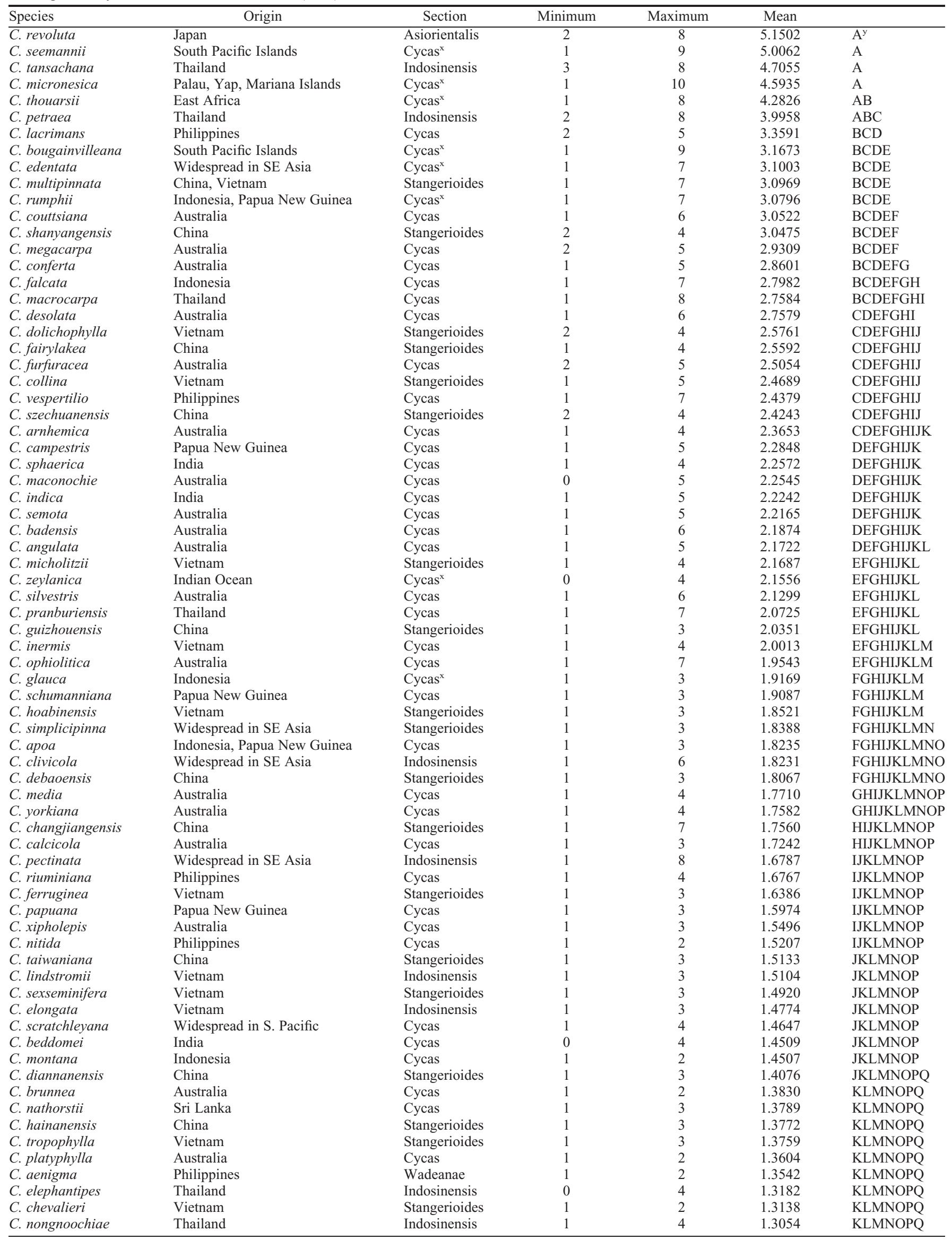


Table 1. (Continued) Extent of Chilades pandava herbivory among 85 Cycas species growing at Nong Nooch Tropical Botanical Garden in Thailand, native biogeographic range, and Cycadaceae section based on Hill (2004). ${ }^{2}$

\begin{tabular}{|c|c|c|c|c|c|c|}
\hline Species & Origin & Section & Minimum & Maximum & Mean & \\
\hline C. cairnsiana & Australia & Cycas & 1 & 2 & 1.2931 & KLMNOPQ \\
\hline C. panzhihuaensis & China & Asiorientalis ${ }^{\mathrm{w}}$ & 0 & 3 & 1.2769 & LMNOPQ \\
\hline C. chamaoensis & Thailand & Indosinensis & 1 & 3 & 1.2647 & MNOPQ \\
\hline C. pruinosa & Australia & Cycas & 1 & 2 & 1.1144 & NOPQR \\
\hline C. circinalis & India & Cycas & 1 & 2 & 1.0967 & OPQR \\
\hline C. wadei & Philippines & Wadeanae & 1 & 2 & 1.0598 & OPQR \\
\hline C. pachypoda & Vietnam & Indosinensis & 0 & 2 & 1.0592 & PQR \\
\hline C. aculeata & Vietnam & Stangerioides & 0 & 1 & 0.5947 & $\mathrm{R}$ \\
\hline
\end{tabular}

${ }^{2}$ Means of three evaluators, $0=$ no damage, $10=$ extensive damage.

${ }^{y}$ Means with the same letter are not significantly different.

${ }^{\mathrm{x}}$ Subsection Rumphiae.

${ }^{\text {wRecent }}$ evidence supports change to Stangerioides section.

Biogeography. Cycas is a widespread genus comprised of species that range geographically from strict endemics to some widespread species (Table 1). Native geographic range at the country or regional level is also not useful for explaining the differences that we found among these 85 species. Although the gross geographic region of origin does not appear to be useful for understanding the differences in butterfly damage among Cycas species, there may be explanations for the diversity in damage noted within a country or region. We propose that identifying the Cycas species possessing a native habitat that is shared with the butterfly may be informative. Four subspecies of this cycad specialist Lycaenidae species are currently recognized. Chilades pandava lanka is known from Sri Lanka, Chilades pandava peripatria occurs exclusively in Taiwan, Chilades pandava vapanda occurs in the Philippines, and the widespread Chilades pandava pandava is found in mainland China and Southeast Asia (Hsu, 2002; Igarashi and Fukuda, 2000; Wu et al., 2010). The precise genotype of the population we studied at Nong Nooch Tropical Botanical Garden is not known but is likely an admixture of Chilades pandava pandava introductions from numerous locations. The closely related Lycaenidae specialist Theclinesthes onycha occurs in Australia (Braby, 2004; Forster and Machin, 1994). The eight Cycas species that assemble as the least damaged species (Table 1) occur within these prescribed geographic ranges.

For the Australian Cycas species exhibiting greater than average butterfly damage in our survey, these may occur outside the constrictions of Queensland and New South Wales that comprise the contiguous native range of $T$. onycha (Braby, 2004). Furthermore, any evolved reactions of a Cycas species to $T$. onycha herbivory may not translate to how that Cycas reacts to a different genus or species of herbivore. A full understanding of why some Cycas species are susceptible to butterfly damage despite their nativity within known butterfly range is more elusive. An example is $C$. tansachana, which is heavily damaged by butterfly relative to the entire list of Cycas (Table 1). Cycas tansachana is endemic to a small limestone outcrop with extremely high surface temperatures. We suspect that this butterfly cannot thrive in this habitat despite its location within the indigenous range for the butterfly. The details of field conditions to validate these habitat-specific relationships will require direct observations of butterfly behavior in situ.

Mechanisms and caveats. The specificity of lepidopteran larvae to feed on particular host plant genotypes is well studied (Ehrlich and Raven, 1964). We have discussed potential underlying mechanisms that explain the disparity in butterfly feeding behavior in relation to Cycas species (Marler et al., 2012). One mechanism may be an informationmediated system that is founded in differences in constitutive or induced leaf volatiles that searching female butterflies may use as advertisements for suitable tissue for larval development (Bernays and Chapman, 1994). This mechanism could be tested with oviposition choice tests whereby reproductive female butterflies are simultaneously provisioned with expanding leaves of least-damaged vs. mostdamaged Cycas species. An alternative mechanism may be a resource-mediated system that is founded in differences among the Cycas species for leaf palatability and defense traits. This mechanism may be expressed within the most damaged species as greater abundance or diversity of phagostimulants for feeding caterpillars and/or slow development of leaf toughness as leaves expand. Alternatively, it may be expressed within the least damaged species as constitutive or induced plant substances that inhibit caterpillar feeding and/or rapid leaf growth out of the soft, vulnerable tissue stage. Relevance of this resource-mediated mechanism could be tested with caterpillar bioassays that determine survival and growth rates among caterpillars reared on expanding leaf tissue of various Cycas species. We note that many species have individuals exhibiting no discernible butterfly damage (indicated by 0 in Table 1) despite high-density butterfly population pressure and our observation of ovipositioning on all Cycas species. Therefore, these assays should include first instar performance because this stage is highly vulnerable for many Lepidoptera species (Zalucki et al., 2002).
The extant literature illuminates several issues that deserve mention as possible relevant factors for interpreting the results of our study. For this Cycas-Chilades system, we have mentioned (Marler et al., 2012) that tritrophic relations may partly mediate the relationship of the herbivore with the Cycas plant (e.g., Harrewijn et al., 1994). Activity of parasitoids or other natural enemies of butterfly eggs or caterpillars may interplay to explain the highly heterogeneous extent of herbivory at the Cycas species level. In addition, the step of ovipositioning by itself may suppress emission of both constitutive and herbivore-induced volatiles in some plants (Peñaflor et al., 2011). Therefore, disparity in timing of ovipositioning among Cycas species within close proximity may influence the attraction of subsequent gravid female butterflies. Moreover, genotype of neighboring plants may influence herbivore abundance on focal plants (Genung et al., 2012). Consequently, herbivory of an individual Cycas tree within a common garden setting may be influenced by layout of the species within the planting. Our understanding of how these sorts of interactions affect plant-pest relations in cycad biology is nil.

The current literature is also revealing more about belowground and aboveground interactions in relation to arthropod herbivory. For example, leaf herbivory may directly influence root microbiota (Landgraf et al., 2012), yet root microbiota may directly influence aboveground volatile infochemicals produced by plants (Pineda et al., 2012; Schausberger et al., 2012). The Cycas plant rhizosphere is characterized by three-way relations among plant roots, mycorrhizae, and cyanobacteria (Fisher and Vovides, 2004; Muthukumar and Udaiyan, 2002; Norstog and Nicholls, 1997). Little is known about the genotype diversity and function of the microbiome of Cycas in a common garden setting. Preliminary work indicates that cyanobacteria genotype within each coralloid root complex is homogeneous, but within one plant's root system, each coralloid root can be colonized by different genotypes (Costa et al., 1999). The relationship among an in situ population of the butterfly, its host Cycas population, and the natural root symbiont 
populations is not influenced by anthropogenic introductions of non-native organisms.

The caveats discussed here illuminate some of the challenges involved in interpreting research conducted in botanic garden settings. For example, a botanic garden in which leaf damage by the butterfly is highly heterogeneous among closely planted Cycas individuals provides a situation in which these feedback loops between aboveground and belowground relations may become a part of the mechanisms that foster sustained disparity in foliar damage among the Cycas species. Moreover, fertilization and irrigation regimes in managed landscapes may influence the relations of cultivated Cycas plants in a manner that deviates from that in natural habitats. In the current study, microsite variation throughout the garden and disparity in age and size of the trees are among other potentially confounding factors.

We have focused exclusively on one Lycaenidae pest in this discussion, but in the real world, a cycad plant is attacked by multiple herbivores. In Guam, for example, C. micronesica is threatened by a growing list of invasive and native specialist arthropods living in sympatry (Marler and Muniappan, 2006; Marler et al., 2011). The armored scale A. yasumatsui deserves mention as a rapidly invading pest that infests Cycas populations throughout much of the native and invasive Chilades pandava range. Most Cycas trees in Thailand, including within our garden setting, experience minor infestations of this scale pest. An understanding of butterfly herbivory cannot be fully attained if the influences of $A$. yasumatsui and other pests are ignored in the process. For example, Gómez et al. (2012) used individual and combined attack of Tsuga canadensis (L.) Carrière by a scale insect and a gall-forming insect to show that feeding by one arthropod herbivore altered the tissue quality for and damage by the other herbivore.

Horticulture and conservation. Native and invasive populations of Chilades pandava affect horticultural decisions in several ways. First, the aesthetic appeal of susceptible Cycas trees can be entirely removed by the damage imposed on susceptible species (Fig. 1C). In some locations this pest cannot be ignored by landscape managers. Second, the desired homogeneous growth rates needed to reduce costs in any horticultural production system are difficult to achieve for the susceptible Cycas species when this pest is present (Fig. 1E). The growth rates of resistant Cycas species are homogeneous among plants despite chronic butterfly pressure (Fig. 1F). These two factors underscore the importance of understanding the biology of the pest for the best horticultural outcomes and defining the most appropriate means of control. Third, horticulturists would do well to acknowledge their role in conservation, and this case study provides a good example of the complications in fulfilling that role. Introducing non-native Cycas trees into landscapes close to Cycas habitats, especially those of endemic Cycas species, has the potential of disrupting the specialist dependence of the habitat's natural butterfly population on its co-occurring Cycas species. For example, Wu et al. (2010) reported that horticultural plantings of $C$. revoluta in Taiwan lead to irruptions of the native Chilades pandava that in turn increased the threats to the endemic, endangered $C$. taitungensis populations. Cycad conservation plans may be more effective if the role of cycad trees in the life histories of other native organisms is prominently figured into the plans.

Expanding leaves on all Cycas plants in a garden may be frequently sprayed with insecticides for protection against butterfly damage as one means of managing the pest. At Nong Nooch Tropical Botanical Garden, these expensive sprays are applied at weekly intervals. Our results and field observations indicate that one means of improving efficiency would be to eliminate a fixed spray regime on the most resistant Cycas species. If the Cycas species comprising the least damaged taxa could be positioned together in the garden landscape, then this section of the garden could be avoided during sprays applied on a fixed schedule. This may result in substantial reduction in pesticide costs and would also allow limited human resource effort to focus more heavily on protecting the susceptible species.

Some or all of the disparate mechanisms and caveats that we discussed here may mediate the relationships between Chilades pandava and comingled Cycas species in a garden landscape. The real situation likely is a conflation of multiple mechanisms.

\section{Literature Cited}

Bernays, E.A. and R.F. Chapman. 1994. Host-plant selection by phytophagous insects. Chapman and Hall, New York, NY.

Braby, M.F. 2004. The complete field guide to butterflies of Australia. CSIRO Publishing, Collingwood, Australia.

Costa, J.-L., P. Paulsrud, and P. Lindblad. 1999. Cyanobiont diversity within coralloid roots of selected cycad species. FEMS Microbiol. Ecol. 28:85-91.

Dehgan, B. and C.K.K.H. Yuen. 1983. Seed morphology in relation to dispersal, evolution and propagation of Cycas L. Bot. Gaz. 144:412418.

Ehrlich, P.R. and P.H. Raven. 1964. Butterflies and plants: A study in coevolution. Evolution 18: 586-608.

Fisher, J.B. and A.P. Vovides. 2004. Mycorrhizae are present in cycad roots. Bot. Rev. 70:16-23.

Forster, P.I. and P.J. Machin. 1994. Cycad host plants for Lilioceris nigripes (Fabricius) (Coleoptera: Chrysomelidae) and Theclinesthes onycha (Hewitson) (Lepidoptera: Lycaenidae). Aust. Entomol. 21:99-102.

Genung, M.A., G.M. Crutsinger, J.K. Bailey, J.A. Schweitzer, and N.J. Sanders. 2012. Aphid and ladybird beetle abundance depend on the interaction of spatial effect and genotypic diversity. Oecologia 168:167-174.

Gómez, S., C.M. Orians, and E.L. Preisser. 2012. Exotic herbivores on a shared native host: Tissue quality after individual, simultaneous, and sequential attack. Oecologia 169:1015-1024.
Harrewijn, P., A.K. Minks, and C. Mollema. 1994. Evolution of plant volatile production in insect-plant relationships. Chemoecology 5: $55-73$.

Hill, K.D. 2004. Character evolution, species recognition and classification concepts in the Cycadaceae, p. 23-44. In: Walters, T. and R. Osborne (eds.). Cycad classification: Concepts and recommendations. CABI Publishing, Cambridge, MA.

Hsu, Y.F. 2002. Butterflies of Taiwan. National Fonghuanggu Bird Park, Nantou, Taiwan.

Igarashi, S. and H. Fukuda. 2000. The life histories of Asian butterflies. Tokai University Press, Tokyo, Japan.

Landgraf, R., R.S. Schaarschmidt, and B. Hause. 2012. Repeated leaf wounding alters the colonization of Medicago truncatula roots by beneficial and pathogenic microorganisms. Plant Cell Environ. 35:1344-1357.

Lindström, A.J., K.D. Hill, and L.C. Stanberg. 2008. The genus Cycas (Cycadaceae) in the Philippines. Telopea (Syd.) 12:119-145.

Marler, T.E. and J.H. Lawrence. 2012. Demography of Cycas micronesica on Guam following introduction of the armoured scale Aulacaspis yasumatsui. J. Trop. Ecol. 28:233-242.

Marler, T.E., A. Lindström, and L.I. Terry. 2012. Information-based or resource-based systems may mediate Cycas herbivore interactions. Plant Signal. Behav. 7:760-762.

Marler, T.E. and R. Muniappan. 2006. Pests of Cycas micronesica leaf, stem, and male reproductive tissues with notes on current threat status. Micronesica 39:1-9.

Marler, T.E., L.S. Yudin, and A. Moore. 2011. Schedorhinotermes longirostris (Isoptera: Rhinotermitidae) on Guam adds to assault on the endemic Cycas micronesica. Fla. Entomol. 94: 699-700.

Moore, A., T.E. Marler, R. Miller, and R. Muniappan. 2005. Biological control of cycad aulacaspis scale on Guam. The Cycad Newsletter 28:6-8.

Muthukumar, T. and K. Udaiyan. 2002. Arbuscular mycorrhizas in cycads of southern India. Mycorrhiza 12:213-217.

Norstog, K.J. and T.J. Nicholls. 1997. The biology of the cycads. Cornell Univ. Press, Ithaca, NY.

Osborne, R., M. Calonje, K. Hill, L. Stanberg, and D.W. Stevenson. 2012. The world list of cycads. Mem. N. Y. Bot. Gard. 106:480-508.

Peñaflor, M.F., M. Erb, C.A. Robert, L.A. Miranda, A.G. Werneburg, F.C. Dossi, T.C. Turlings, and J.M. Bento. 2011. Oviposition by a moth suppresses constitutive and herbivore-induced plant volatiles in maize. Planta 234:207-215.

Pineda, A., R. Soler, B.T. Weldegergis, M.M. Shimwela, J.J.A. van Loon, and M. Dicke. 2012. Non-pathogenic rhizobacteria interfere with the attraction of parasitoids to aphidinduced plant volatiles via jasmonic acid signaling. Plant Cell Environ. (in press).

Schausberger, P., S. Peneder, S. Jürschik, and D. Hoffmann. 2012. Mycorrhiza changes plant volatiles to attract spider mite enemies. Funct. Ecol. 26:441-449.

Wu, L.-W., S.-H. Yen, D.C. Lees, and Y.-F. Hsu. 2010. Elucidating genetic signatures of native and introduced populations of the Cycad Blue, Chilades pandava to Taiwan: A threat both to Sago Palm and to native Cycas populations worldwide. Biol. Invasions 12:26492669.

Zalucki, M.P., A.R. Clarke, and S.B. Malcolm. 2002. Ecology and behavior of first instar larval Lepidoptera. Annu. Rev. Entomol. 47:361-393. 